Letras, Lima 48 (84-85): 121-134, 1976.

\title{
Un problema de atribución en literatura colonial peruana: Demofonte y Filis - Telémaco en la isla de Calipso
} EDUARDO HOPKINS RODRIGUEZ

En 1950, Rubén Vargas Ugarte publica las obras de don Lorenzo de las Llamosas (1655-17 ...) (1), cuyo texto más importante lo constituye el poema Demofonte y Filis. Relata éste cómo Demofonte, hijo de Teseo, luego de haber contribuido a la destrucción de Troya, retorna a Atenas. La escuadra del príncipe victorioso naufraga y se refugia en Tracia. Demofonte es socorrido por Filis quien, habiendo muerto sus padres-Licurgo y Cristumenagobierna en la región. Ligados ámorosamente dos dos jóvenes viven juntos hasta que Demofonte se ve obligado a partir hacia Atenas, prometiendo un pronto retorno. Filis, desesperada por los celos ante la creciente demora del amante, cuya traición supone, se suicida. Alrededor de esta trama se agrupan diversos episodios secundarios: percances amorosos entre acompañantes de Demofonte y su consorte; escenas de cacería; luchas, etc.

De argumento muy semejante es la "Epopeya amorosa" de Telémaco en la isla de Calipso, de don Pedro Joseph Bermúdez de la Torre y Solier (1661 (62)-1746): Telémaco, en compañía de su ayo y maestro, Mentor, buscando a su padre Ulises, sufre la destrucción de sus naves a causa de una tempestad. En la isla Ogigia es protegido por la reina Calipso; ésta se enamora de Telémaco, quien, a su vez, se inclina por Eucaris, ninfa de Calipso. Telémaco escapa, dejando a Eucaris, lo cual persuadida de su traición muere

(1) Obras de don Lorenzo de las Llamosas. Introducción $y$ notas de Rubén Vargas Ugarte. Lima, Talleres Gráficos de la Tipografía Peruana, 1950. (Clásicos Peruanos, t. III). 
de pena y desengaño. Es de notar que los celos de Calipso constituyen parte fundamental de la trama. También aquí tenemos varios episodios amorosos paralelos al principal.

Luego trataremos en detalle las relaciones entre estos dos poemas. Por lo pronto, examinaremos las condiciones de los manuscritos que contienen a dichos textos.

Demofonte y Filis. Vargas Ugarte se basa para su edición en cuatro códices, que él denomina, respectivamente, Velasco, Quitense, Jesuítico y Vargas. Los tres primeros se hallan en Quito (Ecuador), el último es propiedad del mismo Vargas Ugarte. Por la descripción que de estos manuscritos realiza el editor, nos enteramos que el primero - Códice Velasco- ha sido muy alterado por el Padre Juan de Velasco, uno de sus antiguos poseedores. Vargas Ugarte nos informa de las "adiciones y correcciones que Velasco se permitió introducir en la obra de nuestro poeta, obligado, según él dice, por las deficiencias y fallas de la copia de que se había servido" (2). Este manuscrito está fechado en 13 de noviembre de 1730 (3) y es el único de los cuatro que posee datación. El Códice Quitense, no menciona el supuesto título de Demofonte y Filis, además le "faltan 2 ff. y del canto sexto falta la primera octava" (4). De igual manera, el Códice Jesuítico carece de algunos folios y, "en general, guarda estrecha semejanza con el Códice Quitense, pero no es tan completo" (5). En el Códice Vargas, por su parte, "se transcribe el poema de Llamosas, sin título alguno, pues el Canto I comienza en los dos últimos versos de la octava, sexta". Vargas agrega que "al final se copian algunas octavas que pertenecen al Canto $\mathrm{V}$ y el Canto último, o sea Los Suspiros, carece de las estrofas que registran los códices gie, 2 yc $3^{\prime \prime \prime}(6)$. Lonverso"

De la descripción realizada por Vargas es posible concluir que las referencias a la autoría de Llamosas son muy vagas. Por ejemplo, en cuanto al primer códice debemos aceptar simplemente la opinión del Padre Juan de Velasco, quien "en la "Introducción" nos dice que algunos creen haber sido el autor de Demofonte y Filis un Fray Antonio de las Llagas, religioso capuchino, aun cuando él no participa de esta opinión" (7). El segundó códice presenta un encabezamiento sumamente impreciso: "Poesías que se hallaron entre las alhajas apreciables de D. Lorenzo Llamosas" (8). Los códices tercero y cuarto no mencionan a Llamosas (9).
(2) Ibíd., p. XIX.
(3) Ibíd., p. XXIX.
(4) Ibíd., p. $\mathrm{XXX}$.
(5) Ibíd., p. XXXI.
(6) Loc. cit.
(7) Ibíd., p. XXI.
(8) Ibid., p. XXX.
(9) Ibíd., pp. $\mathrm{XXX}-\mathrm{XXXI}$.

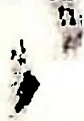


Súmese a la inseguridad apreciada sobre el supuesto autor, las condiciones de los manuscritos, que podríamos, de acuerdo con las explicaciones de Vargas en su"Introducción" y nota bibliográfica a la edición de Llamosas, resumir así (10):

-Manuscritos incompletos.

-Desorden y variantes en la secuencia de las octavas.

- Versos ilegibles, borrados y sin concluir, como en el caso del Códice Velasco.

-En tres de los manuscritos no se encuentra el título del poema; nominación que sólo aparece en la dudosa versión conservada por el Padre Velasco.

Telémaco en la isla de Calipso. El manuscrito de este poema se encuentra en la Biblioteca Nacional de Lima conformando un volumen que incluye además una "Oración Académica "titulada Obsequio de la memoria... (11). El códice lleva el siguiente encabezamiento: "Telémaco / en la Isla de Calipso / Epopeya Amorosa / Escrita y dividida en quatro cantos Por el / Doctor Don Pedro Joseph Bermúdez de / la Torre y Solier, / Alguacil Mayor de la Real Audiencia de Lima. / Dedicada al Excmo. Señor Conde de la Monclova, / Virrey del Perú. / Y después de esta Epopeya Amorosa se pone / Una Oración Académica, que intituló el Autor / Obsequio de la Memoria / En Lima. Año de $1728^{\prime \prime}$. Se repite este encabezamiento, abreviado, al comienzo del Canto I.

El "Prólogo" de Bermúdez da clara cuenta de la fuente utilizada para componer su obra: Aventuras de Telémaco, hijo de Ulises, de Fenelón. El autor ihcluye un resumenorgumental de este libro. Afirma Bermúdez haber escrito su "Epopeya Amorosa" a instancias del Conde de la Monclova, virrey del Perú, a quien dedica su poema. Interesa remarcar que en este "Prólogo" el autor indica que algunas aventuras contenidas en el Telémaco de Fenelón han sido excluidas y que, en cambio, se ha incorporado "algunos episodios de invención propia" (f. VI, v.).

Sigue al "Prólogo" un soneto "en alabanza del Autor y de la Obra", por don Luis A. de Oviedo y Herrera, Conde de la Granja. Aunque no menciona el título del poema, se refiere a éste como "Epopeya Amorosa", tal como también se lo denomina en la inscripción inicial del códice. Dice el soneto:

(10) Ibíd., p. XVIII y ss.; p. XXIX y ss. Véase también: Rubén Vargas Ugarte. Manuscritos peruanos en las bibliotecas de América. Buenos Aires, Talleres Gráficos de A. Bariocco y Cia., 1945, t. IV, pp. 160 y $163-165$.

(11) Luis Alberto Sánchez da por desconocida esta "Oración Académica". Cf. su La literatura peruana; derrotero para una historia cultural del Perú. Lima, Ediciones de Evidentas, 1965, t. II, p. 518. 
Pero en esta Epopeya que Amorosa Vuestro ingenio intitula,...

Un elogio poético de Fray Juan Theodoro Vásquez, hace referencia a las octarvas en que está organizado el poema:

Cada octara es un Poema ingenioso.

En la décima de don Blas de Ayessa, "del Orden de Calatrava, Secretario de Su Majestad, y de Cámara del Excmo. Sor. Conde de la Monclova, Virrey destos Reinos del Perú, Tierra firme y Chile", se nombra a dos de los personajes principales de la "epopeya" - Telémaco y Eucaris- con relación a su alabado escritor.

Por último, un soneto del Contador don Juan de la Vega Coronel, consigna el apellido del autor:

\section{A ti solo es posible tu alabanza, gran Bermúdez...}

De otra parte, antecede a cada canto su respectivo "argumento". Luego de concluido el poema, encontramos un soneto, en el cual el autor (no se lo nombra) ofrece el volumen, con sus dos partes, a D. Joseph de la Puente Larrea.... Marqués de Sotomayor, etc. El manuscrito aclara los yersos 3 y 4 del soneto:

\section{Ya de un Joven * en Líricas Historias \\ Ya en ibjasones cä de tanto ínclito Numen}

Según Bermúdez (fol. V. vivgl]" "se formós esta "Epopeya amorosa" por orden del Excelso Mecenas, a cuyo esclarecido Nombre la consagró el afectuoso rendimiento que por superior precepto suyo la escribió...". El tal "Mecenas", sabemos por los encabezamientos del volumen, es el virrey Conde de la Monclova. En la octava 7a. (Canto I) el v. 8 dice: "La América os clama su Columna"; una nota al margen explica que Columna es anagrama de Monclova. Al respecto, las tres octorvas primeras del Canto IV, según anota el manuscrito "son Acrósticas y contienen en las Letras iniciales de sus Versos el Nombre del Héroe del Poema, el Título del Mecenas a quien se dedicó, y el Apellido del Autor que le compuso". Esto es: TELEMACO, MON CLOVA, VERMUDEZ. Como última mención de autoría, tenemos la anotación de $\mathrm{Pe}$ dro de Peralta Barnuevo, en su Lima Fundada:

[Bermúdez] Tiene que dar á luz las obras que ha discurrido en prosa y metro, como son un tratado sobre ser punto de fé la muerte de los hombres, una epopeya amorosa, en cuatro cantos, de Telémaco en la isla de Calipso y otras que 
atesora manuscritas, y serán otro Perú de intelectual pero mejor riqueza.

Esta nota acompaña a la octava CLXII (Canto $7^{\circ}$ ):

A aquel, que con la pluma y con la lira, Uniendo lo florido y lo canoro,

Del temple y de las Piérides que inspira A un tiempo es todo el prado y todo el corci Este el Bermúdez es, que tanto admira, Tan elocuente es y tan sonoro, En el plectro ó la voz, que incomparable, Si él mismo no se influye, no es cantable. (12)

En conclusión, esta obra se nos presenta avalada por una serie de personajes importantes en su época, quienes consideran y aprecian a Bermúdez como su autor. A esto se suman indicios como el del nombre de Bermúdez, del mecenas y del héroe del poema, en sendos acrósticos. Destácase el buen estado del manuscrito y la conservación del texto íntegro, con sus respectivos prólogo, alabanzas, argumentos de los cantos, etc.

Fuera de las anotaciones que corresponden al anagrama, acrósticos y soneto, antes mencionados, el códice de Bermúdez ostenta numerosas indicaciones marginales en latín y español, que explican las alusiones o las fuentes de ciertos conceptos poéticos, siguiendo en esto una costumbre erudita peculiar de los textos cultos de la literatura peruana en la Colonia (13). Ninguna de tales notas se reproduce en "elolDemofonte yl Filis, vublicado por Vargas Ugarte.

Nos interesa especialmente exponer dos de esas citas, por ser ilustrativas de un procedimiento de carácter áulico, propio de la época, y porque manifiestan de modo más acentuado que las otras anotaciones -más bien eruditas - la voluntad intencional del autor frente a su composición:

a) "En la relación Poética de las heroicas prendas de Telémaco se hace una descripción Alegórica de las Reales virtudes de nuestro invicto Monarca Don Felipe Quinto (que Dios guarde) cuyas fieles noticias ha esparcido diligente la Fama

(12) Manuel de Odriozola. Documentos literarios del Perú. Lima, Establecimiento de Tipografía y Encuadernación de Aurelio Alfaro, 1863, t. I, p. 233.

(13) Cf. Telémaco..., Canto III, 96, v. 2; Canto IV, 1, v. 1; 7, v. 8; 75 , v. $8 ; 115$, v. $7 ; 116$, v. $6 ; 129$, v. $4 ; 133$, v. 3 ; Soneto al final del poema, vv. 3-4. 
por los dilatados espacios de la leal América". (Canto IV, 129).

b) "Mentor representa aora aquí alegóricamente la Real Persona del esclarecido Rey Christianíssimo de Francia Luis Dézimo Quarto el Grande, ínclito Ábuelo de nuestro Español Cathólico Monarca. Y a esta Alegoría da hermosa proporción lo que dice Homero en el libro $1^{\circ}$ de la Ulisea, assentando que Mentor era Rey de los Tahios". (Canto IV, 133).

La comparación de los dos textos en cuestión -el de Bermúdez y el que se atribuye a Llamosas- nos permitirá afirmar que $D e-$ mofonte y Filis no es más que una caprichosa construcción elaborada a partir del poema de Telémaco en la isla de Calipso.

Proponemos a continuación una muestra comparativa de octavas provenientes de ambos poemas.

1.- Yo que en la flor de mis primeros años Canté de Amor las dulces tiranías, Y en celebrar sus agradables daños Passé las horas sin lograr los días: Aora en numerosos desengaños (Si llanto son las consonancias mías) Del mismo amor haré correr velozes Las lágrimas por ecos de mis vozes.

\section{Biblioteca de (Telém. "Canto I, 1)}

Yo qure en lacflorlde mis primeros años Canté de amor las dulces tiranías.

Y en los hechizos de agradables daños

Mentí las horas y engañé los días,

Ahora en numerosos desengaños

Si llanto son las consonancias mías,

De la deidad que fue de Grecia espanto

Canto el amor y la tragedia canto.

(Demof., Canto 1, 1)

Como puede notarse, la última octava varía los versos 2 y 3 sin modificar maxyormente el sentido de la estrofa. En cambio, los vv. 7 y 8 sí alteran la estructura significativa, dejando débilmente integrado el v. 6, el cual adquiere plena función y sentido en la estrofa de Bermúdez, al establecerse un coherente y elaborado sistema de correspondencias: 


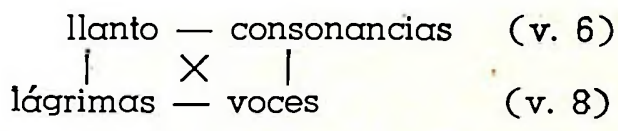

2.- El Xanto undoso que el incendio huía Con ronca voz y lúgubres querellas En lágrimas deshecho parecía Volcán de llanto, y Golfo de centellas: Assí triste paraba, assí corría, Viendo cenizas ya sus flores bellas, Que oyó el silencio de sus grutas ondas Llorar las peñas, y gemir las ondas.

\section{(Telém., Canto I, 99)}

El Xanto turbio que al incendio huía, con ronca voz y lúgubres querellas, en lágrimas deshecho, parecía un mar de llanto, un golfo de centellas así triste pasaba, así corría desaliñando sus arenas bellas, que hizo a la fuerza de sus quejas vagas llorar las peñas y gemir las aguas.

$$
\text { (Demof., Canto } 2^{\circ}, 41 \text { ) }
$$

El v. 4 de la primera octava se organiza en función de una pareja de correlaciones simétricas:

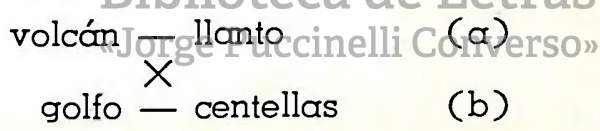

Basándose en la figura del fuego reflejado en el agua, se enfrentan las imágenes $(a)$ y $(b)$, cada una inversión, espejo de la otra. Este esquema se ve empobrecido en la 2a. octana, v. 4, convirtiéndose en una serie casi reiterativa. Ocurre algo similar con el enérgico contraste plástico de cenizas/flores (v. 5 ), que se ve disminuido en el correspondiente v. 5 de Llamosas. Dado el contexto de la estrofa, no se justifica hablar de "quejas vagas" en el v. 8 de Demofonte, habiéndose precisado lo de "ronca voz y lúgubres querellas". Cabe decir que, inclusive, el esquema de la rima consonante no es respetado en los vv. 7 y 8: vagas-aguas.

(14) Se ha utilizado el manuscrito ya citado de Bermúdez y la edición de Llamosas por Vargas Ugarte. Lamentablemente, no hemos podido observar los manuscritos de Llamosas, aunque para los fines de nuestro artículo basta con -la descripción que de ellos realiza Vargas Ugarte y con su publicación de "Clásicos Peruanos". 
3.- Del Globo sublunar, si bien se exprime, Los elementos son Coro no breve:

Tiple es el Fuego que a lo más sublime Sube sutil; Contralto el Ayre leve;

Tenor es la Agua que en las rocas gime Más grave, y a sus números de nieve Baxo es la Tierra, en cuya igual porfía La batalla no es guerra, es armonía.

\section{(Telém., Canto IV, 74)}

Del globo sublunar, si bien se exprime, los elementos son coro no breve triple es el fuego que a lo más sublime sube, sutil contralto al aire leve tenor el agua que en las rocas gime, mar grave, a cuyos números de nieve fundamento es la tierra, en cuya vía la batalla no es guerra es armonía.

(Demof., Canto 99, 31)

Bermúdez da cuenta de los llamados cuatro elementos en términos musicales, conformando, de esta manera, un coro armónico. Esquematizando tendríamos:

Fuego - tiple

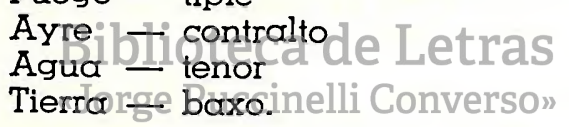

Esto cambia en el caso de Llamosas. No tomaremos en consideración el llamar triple al fuego ( $v .3)$, pues podría tratarse de un error tipográfico; por su parte, el v. 7, al decir "fundamento es la tierra" (subrayamos), rompe la serie comparativa, que se basa en una clasificación de tipo musical. Las otras variantes podrían ser también erratas de imprenta.

4.- A la lengua de la agua entendió luego El gran sucesso, y viendo en solo un punto Que muchas otras le ofrecía el fuego Que de Troya en Salento era transsunto; Por el espanto de las sombras ciego Al escuadrón de los traydores junto Entre las peñas rápido acomete Como el Nilo Hydra al Mar por bocas siete.

(Telém., Canto IV, 89) 
A la lengua del mar poniendo luego

la planta en tierra, y viendo en solo un punto

que muchos riesgos le ofrecía el fuego

con que Atenas de Troya era transunto;

por el espanto de las sombras ciego,

al escuadrón de sus contrarios junto,

entre unas peñas, rápido acomete

como el cielo, hidra al mar, por bocas siete.

\section{(Demof., Canto 9\%, 50)}

El v. 3 (oct. 89 ) incluye una figura retórica favorita del estilo barroco - - Bermúdez se halla ligado a tal estilo- denominada zeugma, que consiste en una construcción de varios enunciados que recurren a un término explicitado sólo en uno de ellos; a veces el término puede ser empleado en distintos sentidos:

\section{Que muchas otras le ofrecía el fuego (v. 3)}

En este verso, lenguas es el elemento no precisado y al que se refiere el adjetivo otras. Dicha figura, tan artificiosamente construida por Bermúdez, se ve anulada en la estrofa 50 (Llamosas):

\section{que muchos riesgos le ofrecía el fuego (v. 3)}

En cuanto al v. 8 de ambas octavas, observamos cómo Nilo cambia a cielo. Por el contexto se deduce que es incorrecta la segunda versión, pues en el primer caso se alude al delta del Nilo: Hydra al mar por bocas siete.

Como resultado de la confrontación entre ambas obras, hemos obtenido un esquema en el cual se observa qué octavas y versos de Demofonte... corresponde a los de Telémaco... Las variantes, generalmente mínimas, entre las estrofas identificadas se deben, en primer lugar, a la necesidad de adecuar el texto base (Telémaco...) a las condiciones del aparentemente nuevo relato de Demofonte... Por ello se produce el cambio de nombre en los personajes (que, a su vez, exigirá la alteración parcial del verso original para mantener el canon métrico), la supresión o adición de otros, etc. De tal necesidad de adecuación se derivan las múltiples interpolaciones estróficas en Demofonte... con respecto a la secuencia de las mismas en Telémaco...

En segunda instancia, las variantes encontradas parecen proceder de una errada lectura de los manuscritos atribuidos a Llamosas; esto debido al mal estado de tales documentos (en ciertos casos, queda la posibilidad de tratarse de errores de imprenta). También hay que señalar las múltiples omisiones que realiza el editor Vargas Ugarte: "Se han suprimido algunas octavas, como se indica 
en el texto, sea porque revelan no tan buen gusto, sea porque constituyen repeticiones innecesarias o, finalmente, por la crudeza de algunas escenas que no añaden ni quitan valor al conjunto" (15). $A$ esto se adhiere el que la edición mencionada utiliza los agregados que el Padre Velasco hizo para completar buen número de octavas e introducir otras en los lugares en que faltaban; todo ello de su personal invención (16).

El esquema comparativo que incluimos a continuación, indica, numéricamente, en su primera columna la secuencia estrófica de Telémaco.... precisando el canto correspondiente. Frente a esta serie, colocamos el número de la estrofa identificada en Demofonte..., agregando, entre paréntesis, la cifra del canto en que se encuentra, según la publicación de Vargas Ugarte. Advertimos que, en la mayoría de los casos, las variantes son ligeras; cuando no fuere así, lo aclararemos en nota a pie de página.

\section{ESQUEMA COMPARATIVO}

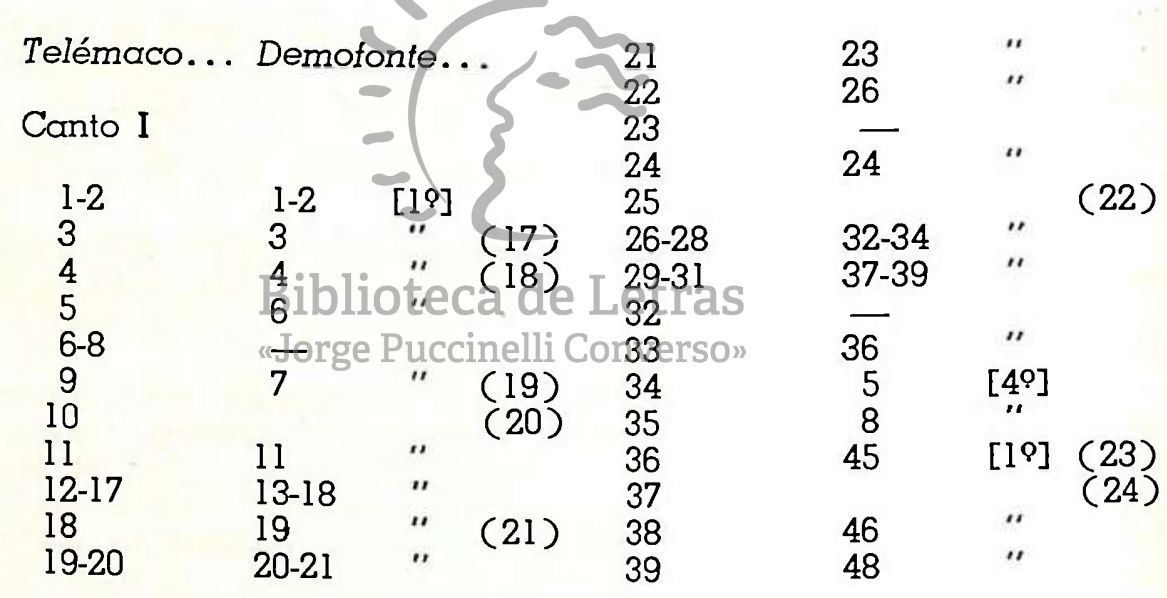

(15) Rubén Vargas Ugarte. Op. cit., p. XXXI.

(16) Ibíd., Canto 89, estrofas 6-12 (nota 3), pp. 106-107; Canto 99, estrofas 89-90 (nota 3), p. 126; Canto 109, estrofas 8-12 (nota 1), pp. 128-130, etc.

(17) V. 8 de Tel.: v. 8 de Dem., estrofa 1, (109).

(18) Solamente son reconocibles algunos versos.

(19) Escasamente identificable.

(20) V. 4 de Tel.: v. 6 de Dem., estrofa 9 (19); vv. 5, 7, 8 de Tel.: vv. 5, 7, 8 de Dem., estrofa 10 (19).

(21) V. 2 de Tel.: v. 4 de Dem.

(22) V. 8 de Tel.: v. 4 de Dem., estrofa 27 (19).

(23) Identidad en los 5 primeros vv.

(24) Vv. 7 y 8 de Tel.: vv. 7 y 8 de Dem., estrofa 45 (19). 


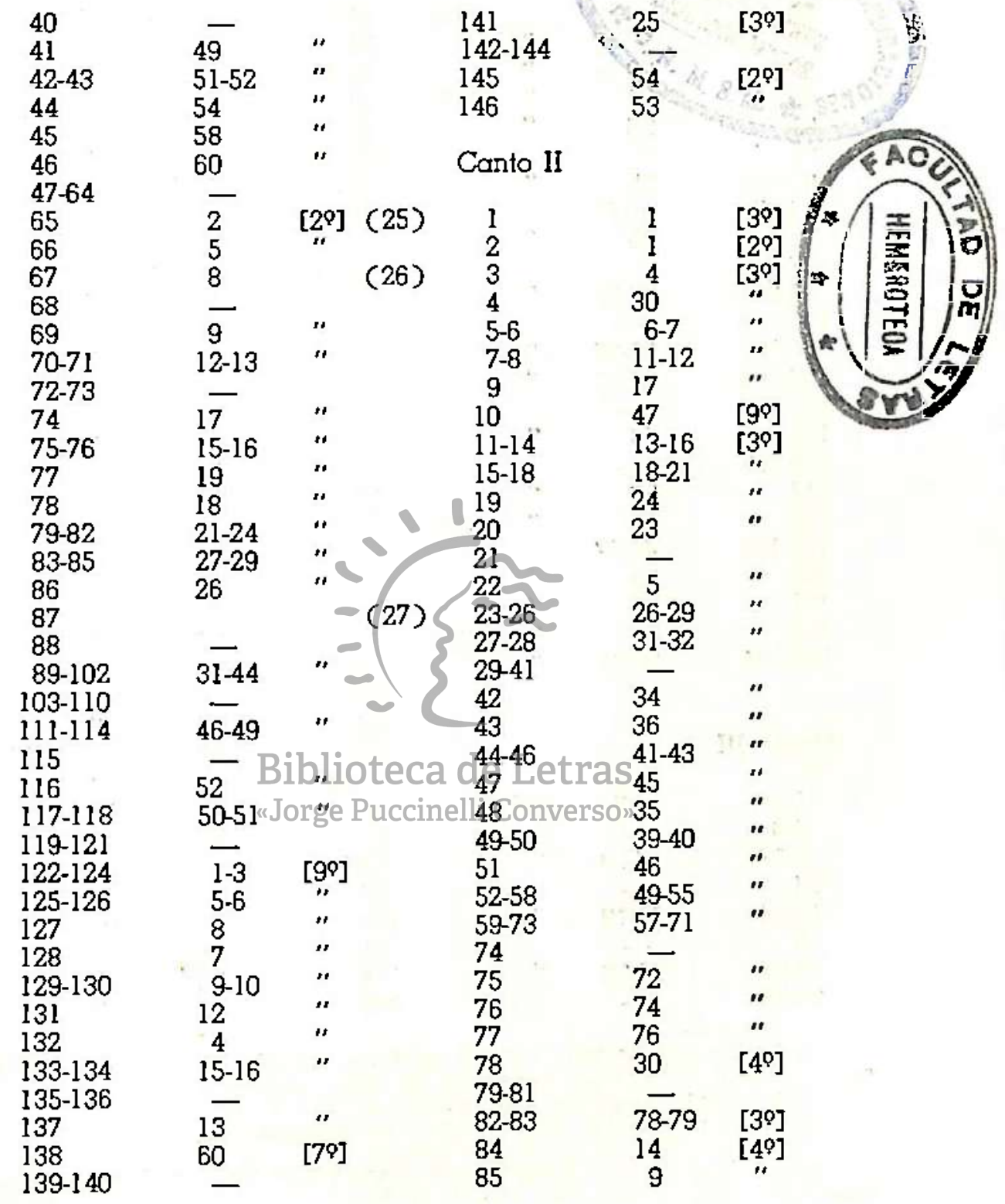

(25) Muchas variantes.

(26) Coinciden los 6 primeros vv. y parte de vv. 7 y 8.

(27) Existen cierta semejanza con la estrofa 27 (29) de Dem. 


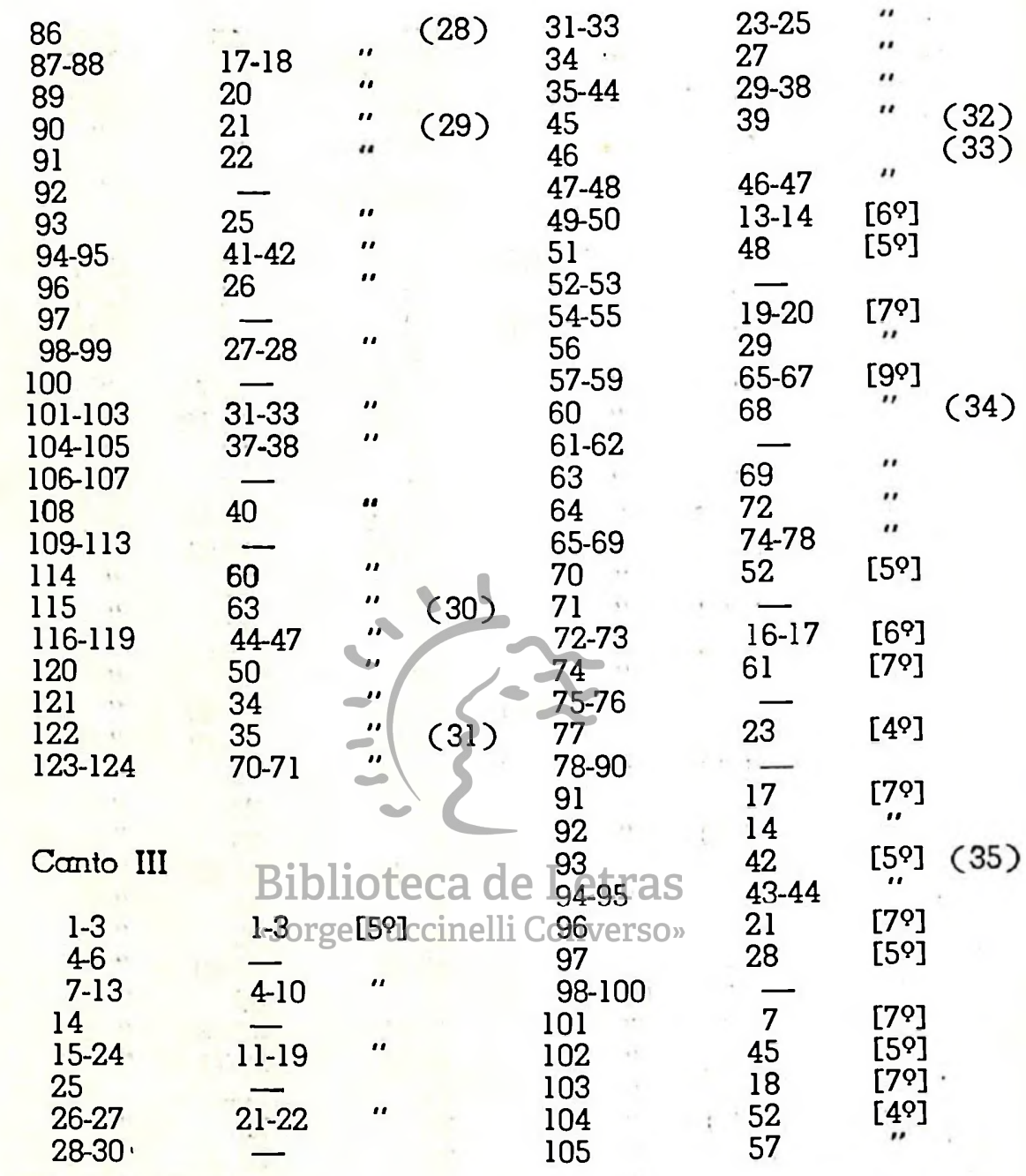

(28) Vv. 1-4 de Tel.: vv. 1-4 de Dem., estrofa 11 (49); vv. 5-8 de Tel.: vv. 1, 2, 7, 8, respectivamente, de Dem., estrofa 12 (49).

(29) Identidad en los 5 primeros vv.

(30) Se reproducen únicamente los 6 primeros vv.

(31) Identidad en los 4 primeros vv.

(32) Coinciden los 4 primeros vv.; vv. 7-8 de Tel.: vv. 7-8 de Dem., estrofa 42 (59). (Véase Tel., Canto III, 93).

(33) Vv. 5, 7, 8 de Tel.: vv. 4, 7, 8, respectivamente, de Dem., estrofa 41 (59).

(34) Coincidencia en los 6 primeros vv.

(35) Identidad en los primeros vv.; v. 8 de Tel.: v. 8 de Dem., estrofa $39\left(5^{\circ}\right)$. 


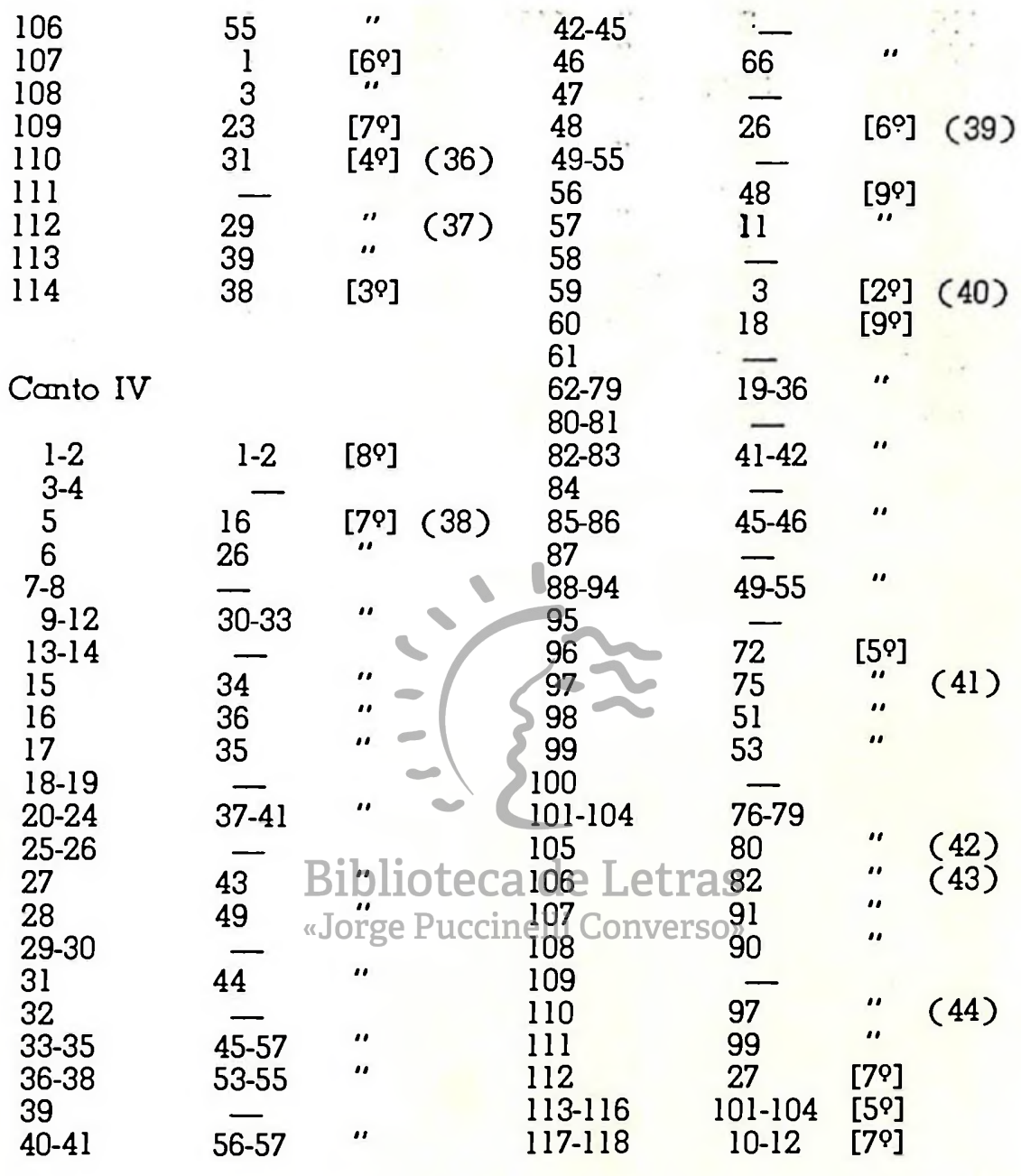

(36) Coinciden los 4 primeros vv., que, a su vez, son semejantes a los vv. 1-4 de Tel., Canto II, 101.

(37) Identidad en los 6 primeros vv.

(38) Se reproducen los 6 primeros vv.; v. 8 de Tel.: v. 2 de Dem., estrofa $9(79)$.

(39) Semejanza en los 4 primeros $v v$.

(40) Se reproducen los 6 primeros vv.

(41) Coincidencia en vv. 7-8.

(42) Igualdad en los 6 primeros vv.

(43) Ibídem.

(44) Ibídem. 


\begin{tabular}{|c|c|c|c|c|c|}
\hline $\begin{array}{l}119 \\
120 \\
121-122 \\
123 \\
124 \\
125-126 \\
127 \\
128 \\
129 \\
130-131 \\
132-134 \\
135 \\
136\end{array}$ & $\begin{array}{c}3 \\
4 \\
36-37 \\
- \\
33 \\
- \\
38 \\
2 \\
35 \\
5-6 \\
56 \\
57\end{array}$ & $\begin{array}{c}\prime \prime \\
{[6 \%]} \\
\prime \prime \\
\prime \prime \\
{[7 \%]} \\
{[6 \%]} \\
{[7 \%]} \\
{[9 \%]} \\
\prime \prime\end{array}$ & $\begin{array}{l}(47) \\
(48)\end{array}$ & $\begin{array}{l}137 \\
138-140 \\
141 \\
142 \\
143 \\
144-145 \\
146-147 \\
148 \\
149-151 \\
152 \\
153 \\
154-155 \\
156\end{array}$ & $\begin{array}{l}58 \\
59-61 \\
67 \\
62 \\
41 \\
- \\
63-64 \\
54 \\
79-81 \\
84 \\
12 \\
85-86 \\
\end{array}$ \\
\hline
\end{tabular}

\section{Biblioteca de Letras "Jorge Puccinelli Converso"}

(45) Identidad en los 7 últimos vv.

(46) Coincidencia en los 5 primeros vv.

(47) Semejanza en los 6 primeros vv.

(48) Se reproducen los 7 primeros vv. 